\title{
Ceftaroline fosamil: development a rapid HPLC method indicating stability and bioassay for determination in pharmaceutical formulation, stability and cytotoxicity studies
}

\author{
Idamir Jose Mascarello Junior*a, Rafaela Martins Sponchiado ${ }^{\mathrm{a}}$, Leticia Malgarin Cordenonsi ${ }^{\mathrm{a}}$, Tércio Oppe ${ }^{\mathrm{a}}$, \\ Elfrides Eva Scherman Shapoval ${ }^{\mathrm{a}}$ \\ ${ }^{a}$ Programa de Pós-graduação em Ciências Farmacêuticas, Universidade Federal do Rio Grande do Sul, Av. Ipiranga \\ 2752, CEP 90610-000, Porto Alegre - RS, Brasil \\ *Corresponding author: ida_junior@hotmail.com
}

\begin{abstract}
The present study reports the development and validation of a microbiological assay. To assess this methodology, the method was developed and validated for the quantification of CEF by high performance liquid chromatography (HPLC). The validation of the microbial assay by diffusion method in $3 \times 3$ cylinder agar presented showed satisfactory results as to specificity, linearity in the range of $2.0-8.0 \mu \mathrm{g} \cdot \mathrm{mL}^{-1}$, precision $(109.42 \%)$, accuracy $(102.3 \%)$ and robustness. The development and validation of the method by HPLC was evaluated according to specificity, linearity, precision, accuracy and robustness. A high performance liquid chromatograph from Shimadzu with Agilent ${ }^{\circledR}$ C18 column, mobile phase (water with triethylamine $1.0 \% \mathrm{pH}$ 5.0: acetonitrile $87: 13 \mathrm{v} / \mathrm{v}$ was used in the chromatographic method. The validated microbiological and chromatographic methods were compared statistically and there was no significant difference between them when compared by Student's t-test. In the preliminary stability study, it was found stable in acid hydrolysis $(0.1 \mathrm{M})$ and UVA light in the period evaluated, and unstable against thermal degradation $\left(40\right.$ and $\left.60{ }^{\circ} \mathrm{C}\right)$, oxidative with hydrogen peroxide $(3.0 \%)$, basic in $\mathrm{NaOH}(0.1 \mathrm{M}$ and $0.01 \mathrm{M})$ and UVC light. Samples exposed to UVC light and thermal degradation at $60^{\circ} \mathrm{C}$ showed degradation kinetics following zero order and second order, respectively. The cytotoxicity assay showed no difference between the normal condition and the sample submitted to forced degradation, suggesting that the possible degradation products formed did not change the result. The methods developed did not present a significant difference, therefore, they are interchangeable, and so can be used for routine quality control analysis.
\end{abstract}

Keywords: ceftaroline fosamil, bioassay, stability, cytotoxicity, HPLC.

Article received at 30/11/2021 and accepted at 20/12/2021.

https://doi.org/10.22456/2527-2616.120343

\section{Introduction}

Antimicrobials, which may be of natural or synthetic origin, are substances that act on the microorganisms inhibiting their growth or causing their death. However, their indiscriminate use coupled with the adaptive capacity of the microorganisms allowed the emergence of resistant strains $(1,2)$. Bacterial resistance to drugs is considered a public health problem, especially in the hospital setting (3).

Cephalosporins are antibacterial belonging to the group of $\beta$-lactams, however more stable in relation to bacterial beta-lactamases and have a large spectrum. They are bactericidal agents that inhibit bacterial cell wall synthesis, this occurs by the inhibition of the enzyme transcriptase, which is responsible for the termination of the cross-links of peptideoglycans that constitute the bacterial cell wall (4-7). In the search for new antimicrobial belongs to the class of cephalosporins, there is Ceftaroline fosamil (CEF) which is a fifth generation cephalosporin that has intravenous use.

CEF (Fig. 1) is a new drug of parenteral use, is converted in vivo into the microbiologically active form, ceftaroline. It was approved by FDA in 2010 for the treatment of skin and soft tissue infections (SSTIs) and Communityacquired pneumonia (CAP). It became part of the therapeutic arsenal in Brazil in 2014 with the name of Zinforo®, marketed by the company Astra Zeneca, in the pharmaceutical form of powder for solution for infusion indicated for the same use as the FDA $(8,9)$

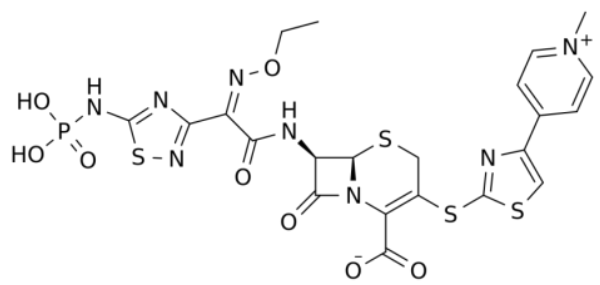

Figure 1: Chemical structure of Ceftaroline fosamil.

Based on the lack of developed and validated methodologies on CEF in its pharmaceutical form, the present study reports the development and validation HPLC and microbiological assay by agar diffusion using the cylinder-plate method. The HPLC method was developed and validated for monitor the microbiological assay. Study of the stability, degradation kinetics and in vitro cytotoxicity were performed to $\mathrm{CEF}$ powder for 
injectable solution. Contribution to the implantation of monographs in official compendia as well as to the quality control of drug.

\section{Material and methods}

\section{Chemicals and Reagents}

The reference substance (RS) of Ceftaroline fosamil (98\%) was obtained from A ChemTek (USA). CEF samples $(600.0 \mathrm{mg})$ were purchased through Victória Comércio de Produtos Hospitalares (Porto Alegre, Brazil), in the commercialized packaging of the drug Zinforo®. Grove Randall number 11 and number 1 agar and tripticase soy broth medium and agar medium were obtained from Merck (Darmstadt, Germany) Acetonitrile HPLC grade was purchased from Vetec (São Paulo, Brazil) Purified water was prepared using Milli-Q Plus ${ }^{\circledR}$ (Millipore, Bedford, USA).

\section{Preparation of standard solutions}

Accurately weighed $1.0 \mathrm{mg}$ CEF reference standard stock was transferred to a $25 \mathrm{~mL}$ volumetric flask with $15 \mathrm{~mL}$ ultrapure water and kept in an ultrasonic bath for $10 \mathrm{~min}$, and the volume was completed with the same solvent obtaining a final concentration of $40 \mathrm{mg} \mathrm{mL}^{-1}$. Aliquots of this solution were diluted sterile ultrapure water to give concentrations of 2.0, 4.0 and $8.0 \mu \mathrm{g} . \mathrm{mL}^{-1}$, which were used in the microbiological assay. In the HPLC method the aliquots of the RS stock solution were removed, diluted in ultrapure water and filtered with a $0.45 \mu \mathrm{m}$ nylon filter for analysis on HPLC.

\section{Preparation of sample solutions}

An amount of powder equivalent to $10 \mathrm{mg}$ CEF was transferred to a $100 \mathrm{~mL}$ volumetric flask with $50 \mathrm{~mL}$ ultrapure water and kept in an ultrasonic bath for $10 \mathrm{~min}$, followed by the dilution to volume with ultrapure water $\left(100.0 \mu \mathrm{g} \cdot \mathrm{mL}^{-1}\right)$. An aliquot of this solution was transferred to a $10 \mathrm{~mL}$ volumetric flask completed with ultrapure water, to obtain the concentrations of 2.0, 4.0 and $8.0 \mu \mathrm{g} \mathrm{mL}^{-1}$, which were used in the microbiology assay. In the HPLC method the aliquots of the sample solution $\left(100.0 \mu \mathrm{g} . \mathrm{mL}^{-1}\right)$ were removed and diluted in ultrapure water. The samples were filtered with a $0.45 \mu \mathrm{m}$ nylon filter for HPLC analysis.

\section{Quantitative analysis by Liquid Chromatographic}

Liquid chromatographic analyses were conducted in a Shimadzu LC-10A system (Kyoto, Japan) equipped with an LC-20AT pump, SPD-20AV UV-VIS variable wavelength detector, DGU-20A5 degasser, CBM-20A controller system, and SIL-20A injection valve with 100 $\mu \mathrm{L}$ loop. Agilent Zorbax Eclipse Plus C18 column $(5 \mu \mathrm{m}$, $250 \mathrm{~mm} \times 4.6 \mathrm{~mm}$ i.d.) were kept at $30{ }^{\circ} \mathrm{C}$. Water:acetonitrile $(87: 13, v / v), 1 \%$ trimethylamine with
pH 5.0 in isocratic mode, at $1.0 \mathrm{~mL} \cdot \mathrm{min}^{-1}$ flow rate was chosen as mobile phase. CEF was determined by UV detection at $242 \mathrm{~nm}$ using a photodiode-array detector.

The system suitability parameters of the chromatographic system were evaluated, and the parameters measured were retention time/capacity factor, resolution, asymmetry, plates and tailing factor.

\section{Microbiological assay}

\section{Microorganism and Inoculum}

Kocuria rizophila ATCC 9341 was purchased in lyophilized form from INCQS (Rio de Janeiro, Brazil) and activated in tripticase soy broth medium and maintained in tripticase soy agar medium. One day before assay, the microorganism was transferred into antibiotic agar medium I and incubated at $35{ }^{\circ} \mathrm{C} \pm 2{ }^{\circ} \mathrm{C}$. A bacterial suspension having a transmittance of $25 \% \pm 2 \%$ at 580 nm, using a spectrophotometer (Analysers, São Paulo, Brazil), was prepared in $\mathrm{NaCl} 0.9 \%$ sterile solution. From this standardized suspension, aliquots were added in Grove Randall 11 medium to obtain a concentration of $1 \%$ kept at $48{ }^{\circ} \mathrm{C}$ and used as the inoculated layer in the plate.

\section{Cylinder-plate assay}

The Grove Randall's 11 culture medium $(20.0 \mathrm{~mL})$ was placed into $100 \mathrm{~mm}$ x $20 \mathrm{~mm}$ Petri dishes for the agar layer. After solidification, $5.0 \mathrm{~mL}$ of Grove Randall's 11 medium with inoculum was added to each dish. In each agar plate six stainless steel cylinders $(8.0 \times 6.0 \times 10.0$ $\mathrm{mm})$ were placed on the surface of inoculated medium, before loading with $200 \mu \mathrm{L}$ of standard (P1, P2 and P3) or sample (A1, A2 and A3) solutions. After incubation at 37 ${ }^{\circ} \mathrm{C}$ for $18-24$ hours, the zone diameters of the growth inhibition were measured $(\mathrm{mm})$ using a digital caliper (Mitutoyo ${ }^{\circledR}$, Tokyo, Japan).

For calculation, graphics plotting logarithm of concentration and inhibition halos diameter were obtained. The statistical analysis was proceeding by treatment of data using the linear parallel model and linear regression analysis, followed by analysis of variance (ANOVA).

\section{Method validation for HPLC and Microbiological assay}

Both microbiological and HPLC methods were validated according to the USP 39 and ICH, 2005 guidance for analytical method validation $(10,11)$. The following parameters of analytical performance were evaluated: specificity, linearity, precision, accuracy, limits of detection and quantification and robustness.

\section{Specificity}

HPLC: was verified through the evaluation of probable degradation products that could interfere in the 
determination. The CEF sample solutions were prepared from a stock solution at the concentration of 500.0 $\mu \mathrm{g} . \mathrm{mL}^{-1}$ using milli-Q water as the diluent. The stress conditions were the following:

Acid hydrolysis: Stock solution of CEF was placed in volumetric flask and $1.0 \mathrm{M} \mathrm{HCl}$ was added for 3 hours, after the specified time of $1.0 \mathrm{M} \mathrm{NaOH}$ was added and was quenched with mili-Q water, obtaining final concentration of $40 \mu \mathrm{g} \cdot \mathrm{mL}^{-1}$.

Basic hydrolysis: Sample solutions were prepared and maintained in $\mathrm{NaOH} 1.0 \mathrm{M}$ for $1 \mathrm{~h}$ and stored at room temperature. After this time, to neutralize degradation was added $\mathrm{HCl} 0.1 \mathrm{M}$, the volume was completed with mili-Q water, obtaining a final concentration of $40 \mu \mathrm{g} . \mathrm{mL}^{-1}$.

Oxidative degradation: Sample solutions were prepared in $\mathrm{H}_{2} \mathrm{O}_{2} 3 \%$ solution and stored at room temperature for 60 minutes. After this time, volume was completed with mili-Q water, obtaining a final concentration of 40 $\mu \mathrm{g} . \mathrm{mL}^{-1}$.

Thermal degradation: Sample solution was kept at $40{ }^{\circ} \mathrm{C}$ and $60{ }^{\circ} \mathrm{C}$ for 120 minutes. After this time, aliquots of this solution were removed and diluted in mili-Q water to achieve a theoretical concentration of $40 \mu \mathrm{g} \cdot \mathrm{mL}^{-1}$.

Photodegradation: The solution stock was added in quartz cells, has been exposed to UVA radiation $(352 \mathrm{~nm})$ and UVC light $(254 \mathrm{~nm})$ for 180 and 90 minutes, respectively. After an aliquot was withdrawn and volume was filled with mili-Q water to final concentration of 40 $\mu \mathrm{g} . \mathrm{mL}^{-1}$.

Microbiological assay: Specificity was studied by analyzing the sample in the presence of the degradation products formed by UVC light and thermal degradation at $60{ }^{\circ} \mathrm{C}$, the same conditions describe above. The sample solutions were prepared at the concentration of $40 \mu \mathrm{g} . \mathrm{mL}^{-}$ 1 , after transfer of aliquots to obtain the concentration of $2.0 ; 4.0 ; 8.0 \mu \mathrm{g} \cdot \mathrm{ml}^{-1}$. The diameter $(\mathrm{mm})$ was compared to the $\mathrm{RS}$ at the same concentrations.

\section{Linearity}

HPLC: Linearity was obtained using $\mathrm{RS}$ in the concentration range of $5.0-60.0 \mu \mathrm{g} \cdot \mathrm{mL}^{-1}$. For each concentration solutions were prepared and injected in triplicate. The results were submitted to the linear regression analysis which was calculated by the least squares method and the analysis of variance (ANOVA) for linear model compliance.

Microbiological assay: three doses of the RS (2.0, 4.0 and $8.0 \mu \mathrm{g} . \mathrm{mL}^{-1}$ ) were evaluated on three different days, each consisting of six plates. Linearity was evaluated by analysis of variance (ANOVA) and the equation of the line obtained by least squares method.

\section{Precision}

HPLC: Method precision was evaluated at two levels: a) repeatability (intraday); and b) intermediate precision (interday). The repeatability was measured as the relative standard deviation of six samples $\left(40 \mu \mathrm{g} \cdot \mathrm{mL}^{-1}\right)$ analyzed in the same day. Intermediate precision was evaluated by the analysis of six samples in three different days. The results were expressed as relative standard deviation (RSD).

Microbiological assay: precision of bioassay method was determinated by repeatability and intermediate accuracy was assessed using the RSD of percent activity values. The assays were performed with CEF samples for 3 different days using six plates in each assay.

\section{Accuracy}

HPLC: accuracy of the method was obtained through the recovery test, where known amounts of RS were added to the sample $\left(5.0 \mu \mathrm{g} . \mathrm{mL}^{-1}\right)$ to yield final concentrations of $15.0,20.0$ and $25.0 \mu \mathrm{g} . \mathrm{mL}^{-1}$.

Microbiological assay: accuracy was performed through the recovery test, where RS solutions were added in a sample solution of CEF in order to obtain values above $10 \%$ of the test concentration $\left(2.2 ; 4.4 ; 8.8 \mu \mathrm{g} . \mathrm{mL}^{-1}\right)$.

\section{Limits of detection and quantification}

HPLC: Limits of detection and quantification were estimated according on a formula that uses the standard deviation of the intercept and inclination, from the linearity curves of the two standards and confirmed through experiments (12).

Microbiological assay: According to the Brazilian pharmacopoeia the limits of detection and quantification are not required for this category of assay (13).

\section{Robustness}

HPLC: robustness of the developed analytical method to changes was tested in a Plackett-Burman experimental design. The factorial design was performed by the selection of three factors, studied at two levels, high and low: percentage of acetonitrile (12-15\%), flow (0.9-1.1 $\left.\mathrm{mL} \mathrm{min}^{-1}\right)$ and column temperature $\left(29-31^{\circ} \mathrm{C}\right)$.

Microbiological assay: Determined by analyzing the sample solution under $\pm 0.2 \%$ variation in the inoculum concentration. The interference of the modifications in the final result was evaluated.

\section{Kinects of CEF degradation}

Sample solutions $\left(500 \mu \mathrm{g} \cdot \mathrm{mL}^{-1}\right)$ were exposed to UVC radiation according to the photodegradation and a thermal $\left(60{ }^{\circ} \mathrm{C}\right)$ degradation studies described in Section Specificy. At pre-established times, $1.0 \mathrm{~mL}$ aliquots of the solution were withdrawn and diluted in water to achieve the concentration of $40 \mu \mathrm{g} \cdot \mathrm{mL}^{-1}$ for HPLC analysis. Aliquots of this solution were diluted in water to achieve concentrations of $2.0,4.0$ and $8.0 \mu \mathrm{g} \cdot \mathrm{mL}^{-1}$ for the bioassay. The degradation order was determined by plotting the graph of concentration vs time (zero order), $\log$ concentration vs time (first order) and inverse of concentration vs time (second order). After determining the order of the reaction, the kinetic models represented 
and the value of $k$ (degradation velocity) were calculed using the following equations (14):

$$
\begin{aligned}
& \mathrm{C}=\mathrm{C}_{0}-k t(\text { zero order reaction) } \\
& \ln \mathrm{C}=\ln \mathrm{C}_{0}-k t(\text { first order reaction) } \\
& 1 / \mathrm{C}=1 / \mathrm{C}_{0}+k t(\text { second order reaction })
\end{aligned}
$$

Where $\mathrm{C}_{0}$ and $\mathrm{C}$ are the concentration of a drug at time 0 and time t, respectively, and $k$ is the constant of reaction.

\section{Cytotoxicity assay}

For the evaluation of cytotoxicity, the MTT reduction assay was performed as previously described (15). This assay measures dehydrogenase activity, an indicator of metabolically active mitochondria, and therefore, of cell viability. Cells were seeded at a density of 35,000 cells $/ \mathrm{mL}$ in 48 -well plates (final volume of $250 \mathrm{~mL} ; 8000$ cells $/ \mathrm{cm}^{2}$ ). The samples exposed to UVC radiation and thermal $\left(60{ }^{\circ} \mathrm{C}\right)$ degradation after 90 and 120 minutes, respectively, after this time was diluted to obtain the concentrations $1.0,10.0,50.0$ and $100.0 \mu \mathrm{g} . \mathrm{mL}^{-1}$. In these cases, $0.1 \%$ DMSO in culture medium was used as negative control. Triton X-100 1\% was used as positive control. After the incubation period, the medium was removed and replaced with fresh medium containing 0.5 mg.L $\mathrm{L}^{-1}$ MTT. The cells were incubated at $37{ }^{\circ} \mathrm{C}$ for $4 \mathrm{~h}$. After incubation, the cell culture medium was removed, and the formed formazan crystals dissolved in DMSO. The absorbance was measured at $550 \mathrm{~nm}$ in a multi-well plate reader (BioTek Instruments, Vermont, USA). To reduce inter-experimental variability, data were normalized and scaled between $0 \%$ (negative controls) and $100 \%$ effect (positive controls). Results were graphically presented as percentage of cell death vs concentration (mM).

\section{Results and Discussion}

\section{HPLC method development and validation}

The chromatographic conditions were adjusted in order to provide a good performance of the assay. During the development of the method by HPLC for the quantification of the CEF, different combinations and proportions of organic solvent, water at different $\mathrm{pH}$ 's, flow and different temperatures were tested. The system suitability parameters of the chromatographic system were evaluated (Table 1) and the best chromatographic conditions used to perform the quantitative analysis by HPLC are demonstrated in Table 2.
Table 1. System suitability parameters obtained experimentally and recommended (SHABIR, 2003; RIBANI, 2004).

\begin{tabular}{llc}
\hline Parameter & \multicolumn{1}{c}{ Recommendation } & $\begin{array}{c}\text { Experimental } \\
\text { value }\end{array}$ \\
\hline Plates & $\begin{array}{l}\text { In general it showed be greater } \\
\text { than 2000 for HPLC. }\end{array}$ & 4498.57 \\
Factor & $\begin{array}{l}\text { Peak must be separated from } \\
\text { other peaks and the unretained } \\
\text { peak k>2. }\end{array}$ & 2.45 \\
Tail factor & $\begin{array}{l}\text { Recommended }<2, \quad \text { very } \\
\text { asymmetric peaks affect } \\
\text { quantification. }\end{array}$ & \\
& & \\
\hline
\end{tabular}

Table 2. Parameters optimized for use in the validation of the method by HPLC for CEF determination.

\begin{tabular}{ll}
\hline \multicolumn{1}{c}{ Parameter } & \multicolumn{1}{c}{ Description } \\
\hline Column & Agilent ${ }^{\circledR}$ Zorbax Eclipse \\
& Plus $\mathrm{C} 18(150 \mathrm{~mm} \times 4.6$ \\
& $\mathrm{mm} ; 5 \mathrm{~m})$ \\
Mobile phase & Water with triethylamine \\
& $1 \% \mathrm{pH} 5.0$ :acetonitrile \\
& $(87: 13 \mathrm{v} / \mathrm{v})$ \\
Injection volume & $20 \mu \mathrm{L}$ \\
Flow & $1.0 \mathrm{~mL} \cdot \mathrm{min}^{-1}$ \\
Detection & $242 \mathrm{~nm}$ \\
Column temperature & $30{ }^{\circ} \mathrm{C}$ \\
\hline
\end{tabular}

\section{Specificity}

The CEF samples solutions were submitted to different stress conditions to induce drug degradation. The degradation study under acid conditions and photolytic UVA radiation, showed stability of the drug in 180 minutes, without formation of degradation product peaks or reduction in the CEF content (Figure 2A and 2D). Thermal degradation at $40{ }^{\circ} \mathrm{C}$ was observed in $180 \mathrm{~min}$ degradation of only $15 \%$, in the thermal $60{ }^{\circ} \mathrm{C}$ in 120 minutes degradation of $55 \%$, and oxidative degradation with hydrogen peroxide in 45 minutes degraded $91 \%$, but no additional peak majority of degradation products was formed (Figure 2C, F and G).

The specificity of the analytical method was established through determination of the peak purity of the analyte, using photodiode-array detector. The peak purity tool, applied to the peak of the sample, demonstrated that $\mathrm{CEF}$ signal was pure in all cases, confirming the absence of the substances coeluting at the same migration times. 


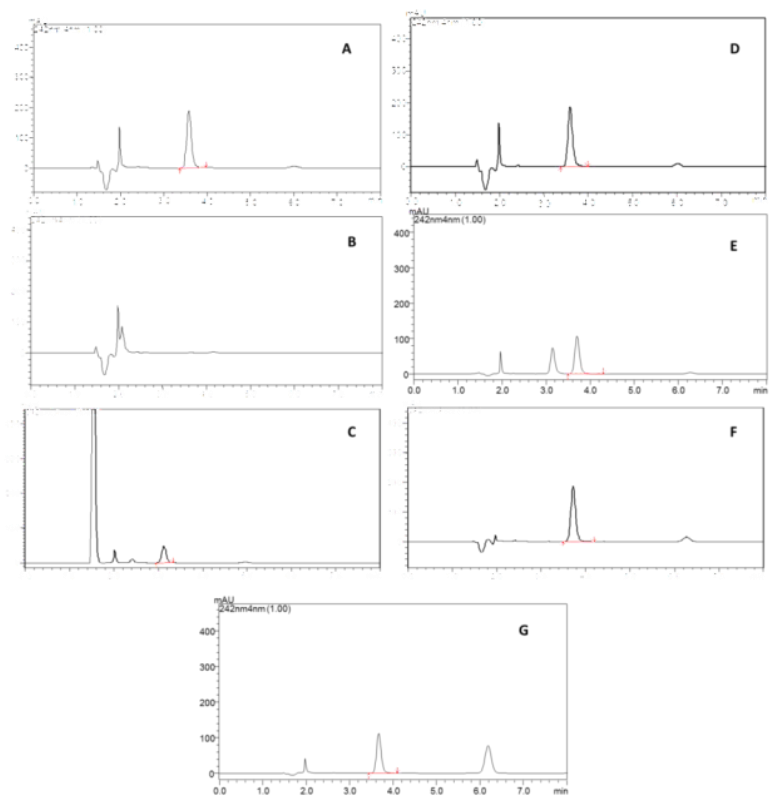

Figure 2. Chromatograms obtained by HPLC analysis of sample solutions exposure to forced degradation: (A) 1.0 $M \mathrm{HCl}$ for $180 \mathrm{~min}$; (B) $0.01 M \mathrm{NaOH}$ for $5 \mathrm{~min}$; (C) $3.0 \%$ of $\mathrm{H}_{2} \mathrm{O}_{2}$ for $45 \mathrm{~min}$; (D) UVA light $180 \mathrm{~min}$; (E) UVC light $90 \mathrm{~min}$; (F) $40{ }^{\circ} \mathrm{C}$ during $180 \mathrm{~min}$; (G) $60{ }^{\circ} \mathrm{C}$ during $120 \mathrm{~min}$.

\section{Linearity}

The method developed presented an appropriate linearity at 5.0-60.0 $\mu \mathrm{g} . \mathrm{mL}^{-1}$ concentration range from 3 days analysis. The mean standard curve equation $\mathrm{y}=64463 \mathrm{x}+$ 5347.6 had a determination coefficient (r2) equal to 0.9996. According to data obtained from ANOVA it is possible to ensure significant linear regression $(\mathrm{p}<0.05)$ and there is no deviation from linearity $(\mathrm{p}>0.05)$.

\section{Precision and Accuracy}

The precision of the method was determined by repeatability (intra-day) and intermediate precision (interday) and it was expressed as RSD (\%). Repeatability was demonstrated by the low RSD found in the samples on the same day (0.54-0.70\%). Regarding the intermediate precision, the RSD value was $0.93 \%$, showed adequate precision of the analytical method.

The accuracy of the method was evaluated by the recovery test, through the analysis of three concentrations in the pre-established range. The mean results were found to be $100.68 \%$, indicating satisfactory accuracy.

\section{Limits of detection and quantification}

Limits of detection and quantification were 0.11 and 0.36 $\mu \mathrm{g} . \mathrm{mL}^{-1}$, respectively. Experimentally, five injections at $0.3,0.4$, and $0.5 \mu \mathrm{g} \cdot \mathrm{mL}^{-1}$ presented an RSD of $0.77 \%$, $1.26 \%$, and $2.20 \%$, demonstrating that the proposed LoQ was precise and sensitive.

\section{Robustness}

In order to study the simultaneous variation of the factors in the considered responses, selected Plakett-Burman desing. The range examine were small deviations from the method setting. The design was successfully applied in the experiments, the effects of each parameter studied (temperature, percentage of acetonitrile and column) were not significant, because the effects calculated were smaller than the critical value of $t(\alpha=0.05)$, and are presented in Figure 3.

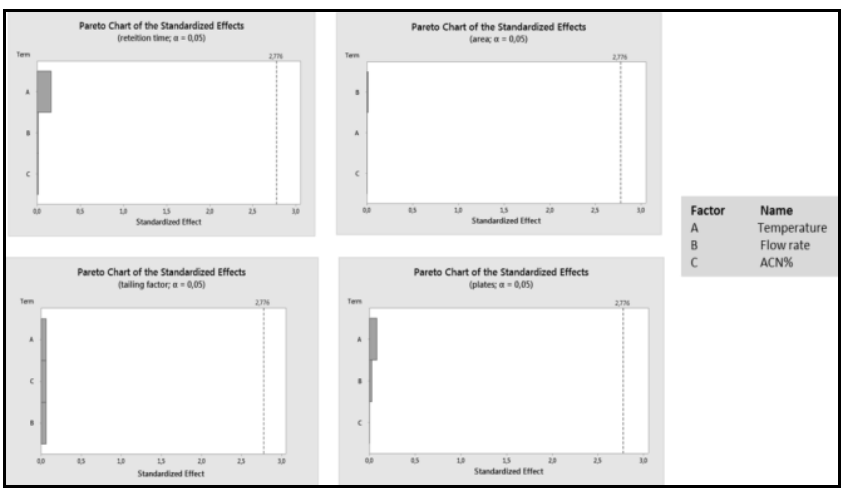

Figure 3. Pareto chart representing the effects of the variables on the CEF assay for the robustness test using the Plackett-Burman design.

\section{Microbiological assay development and validation}

Microbiological test of agar diffusion is a physical method, in which the activity of the antibiotic is defined by the dose that inhibits the growth of a microorganism sensitive to this antibiotic. The assay is performed comparing inhibition of growth of the microorganism by known concentrations of a reference standard with inhibition by dilutions of the test substance $(16,17)$. The assay is a requirement of quality control of several pharmacopoeias $[15,16,10](13,18,19)$.

There are no official monographs for the drug under study with a microbiological method to determine the potency of the antibiotic.

The microbiological assay described in this work was performed in $3 \times 3$ design (three doses of standard and three doses of sample), following the procedure described in the Brazilian (2010) and European Pharmacopoeia (2005). A direct relationship between the observed zone diameter and logarithm of applied dose normally is verified in the calculation.

Preliminary tests were carried out to develop the method such as: RS and sample concentration, incubation temperature, diluent solution and inoculum concentration of the medium in order to determine the ideal experimental condition. Defined parameters are described in Table 3. 
Table 3. Defined parameters established for microbiological assay of CEF.

\begin{tabular}{ll}
\hline Parameter & Description \\
\hline Microrganism & $\begin{array}{l}\text { Kochuria rhizophila ATCC } \\
9341\end{array}$ \\
Culture media & $\begin{array}{l}\text { Medium } \\
\text { number 11 } \quad \text { Grove-Randall }\end{array}$ \\
Diluent solution & Sterile water \\
Standard curve $\left(\mu \mathrm{g} \cdot \mathrm{mL}^{-1}\right)$ & $2.0,4.0$ and 8.0 \\
Inoculum $(\%)$ & 1.0 \\
Incubation time $(\mathrm{h})$ & $18-24$ \\
Incubation temperature $\left({ }^{\circ} \mathrm{C}\right)$ & $35 \pm 2$ \\
\hline
\end{tabular}

Specificity

To show that the microbiological assay is specific, it was necessary to subject the analyte to specific conditions for degradation. Sample solution was exposure to photolytic degradation by UVC radiation and by thermal $\left(60{ }^{\circ} \mathrm{C}\right)$ degradation. The results showed a degradation of approximately $46.26 \%$ when exposed to UVC radiation for 90 minutes, this result being similar to that found by the HPLC method when the same sample was analyzed (44.52\%). CEF exposed to thermal degradation at $60{ }^{\circ} \mathrm{C}$ degraded approximately 55.04\% in 120 minutes, similar to those found by the HPLC method (55.6\%). It was observed that the degradation product formed did not interfere with the determination of the microbiological method for CEF.

\section{Linearity}

The calibration curve of CEF was constructed by plotting $\log$ of concentrations $\left(\mu \mathrm{g} \cdot \mathrm{mL}^{-1}\right)$ versus zone diameter $(\mathrm{mm})$ and shows good linearity in the range of 2.0-8.0 $\mu \mathrm{g} . \mathrm{mL}^{-1}$. The representative linear equation was $y=19,734 x+8,8785$. The correlation coefficient $(r=0.9872)$ was significant for the method. The validity of the assay was verified by means of the ANOVA. According to ANOVA, there is no deviation from parallelism (Fcalculated < Fcritical; p = 0.05) and there is linearity (Fcalculated < Fcritical; $\mathrm{p}=0.05$ ).

\section{Precision and accuracy}

The precision of the assay was determined by repeatability (intra-assay) and intermediate precision (interassay) in which values are expressed as relative standard deviation (RSD) of the series of measurements performed on the same day and on alternate days.

The result obtained shows RSD 1.22 to 1.36 indicating good intra-assay precision. Inter-assay variability was calculated from assays on 3 days and shows RSD of 1.13 (Table 4). The accuracy of the assay was studied. The mean recovery was calculated and was found to be $102.32 \%$.
Table 4. Intra-assay and inter-assay precision data for the CEF bioassay in the pharmaceutical formulation.

\begin{tabular}{llll}
\hline Sample & Day & CEF $^{\mathbf{a}}(\boldsymbol{\%})$ & RSD (\%) \\
\hline 1 & & 108.42 & \\
2 & 1 & 109.72 & 1.23 \\
3 & & 111.12 & \\
1 & & 110.32 & \\
2 & 2 & 107.68 & 1.22 \\
3 & & 109.30 & \\
1 & & 111.04 & 1.36 \\
2 & & 109.03 & \\
3 & 3 & 108.14 & 1.13 \\
\hline
\end{tabular}

${ }^{\mathrm{a}}$ Mean of six determinations.

\section{Robustness}

To evaluate the robustness of the method the concentration of the inoculated medium in the determination of CEF (1.8 and 2.2\%) varied. The values found for the parameter of robustness, with the change in inoculum concentration were $112.12 \%$ and $110.32 \%$, respectively, close to that found by precision (109.42\%), demonstrating the robustness of the method.

\section{Kinetics of CEF degradation}

Results obtained in the preliminary study of stability of $\mathrm{CEF}$, it was decided to verify the kinetics of degradation against UVC light and thermal at $60{ }^{\circ} \mathrm{C}$ for both to have degraded near $50 \%$. All the results obtained through the microbiological assay were monitored by previously validated HPLC. The effects of UVC light and thermal exposure on the residual $\mathrm{CEF}$ and on the pharmaceutical formulation are shown in Tables 5 and 6, respectively. The reaction order for the degradation kinetics of $\mathrm{CEF}$ determined representing the residual drug concentration versus time (zero order reaction), log concentration versus time (first order reaction), and the inverse of a function of concentration versus time (second order). After the coefficient of determination $\left(\mathrm{r}^{2}\right)$ was evaluated, the one closest to 1.0 corresponds to the kinetics of degradation followed. CEF when exposed to UVC light follows zero order kinetics, and this condition could be found both for the microbiological method and for HPLC (Fig. 4A and $\mathrm{B}$, respectively). However, when exposed to thermal conditions follows kinetics of second order, being found this result for the two validated methods (Fig. 4C and D, respectively). Through mathematical calculations, the first reaction rate constant $(k)$ and lifetime $\left(\mathrm{t}_{90 \%}\right)$ were determined. The constant's reaction of the CEF when exposure to UVC light presented mean values of $0.2998 \mathrm{~h}$ and $0.1875 \mathrm{~h}$ and subjected to thermal $\left(60{ }^{\circ} \mathrm{C}\right)$ degradation presented mean values of $0.0001177 \mathrm{~h}$ and $0.000136 \mathrm{~h}$, both evaluated by the chromatographic and 
microbiological method, respectively. The lifetime $\left(\mathrm{t}_{90 \%}\right)$ for CEF when exposure to UVC light showed a value of 12.43 and 19.78 minutes and when subjected to thermal $\left(60{ }^{\circ} \mathrm{C}\right)$ degradation presented a value 23.57 and 20.37, both when evaluated by the chromatographic and microbiological method, respectively.
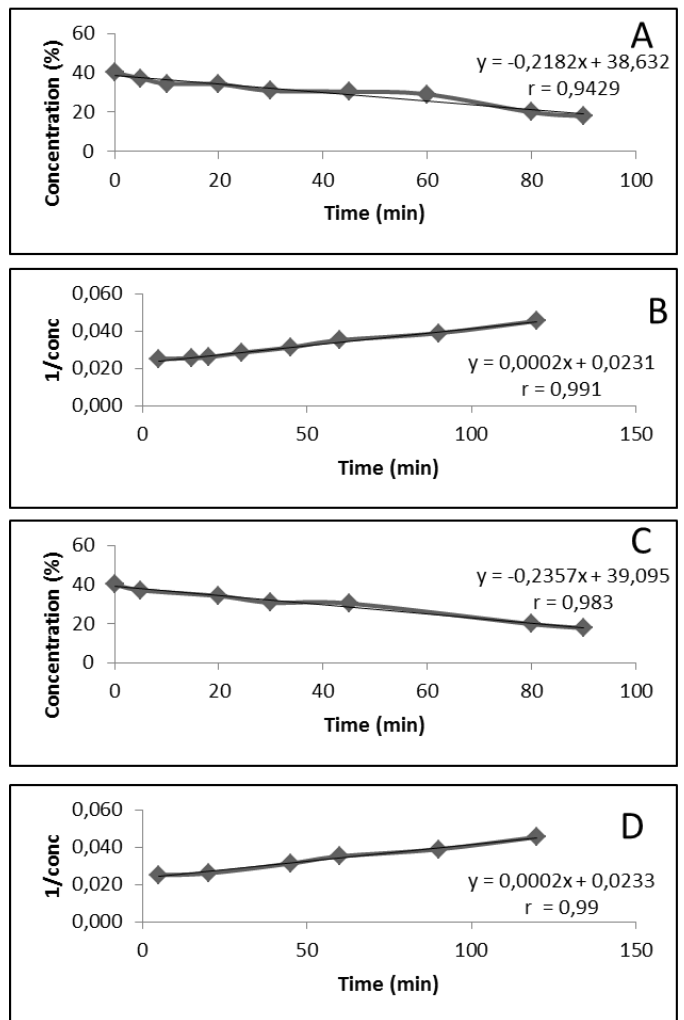

Figure 4. Zero-order plots for the degradation of $\mathrm{CEF}$ under UVC light (A) for HPLC method (B) for microbiological assay. Second-order plots for the degradation of CEF under UVC light (C) for HPLC method (D) for microbiological assay.

Table 5. CEF levels obtained after exposure to UVC light evaluated by HPLC and microbiological assay.

\begin{tabular}{lccc}
\hline HPLC & \multicolumn{3}{c}{ Microbiological assay } \\
\hline Time (Minutes) & CEF (\%) & Time (Minutes) & CEF (\%) \\
\hline 5 & 92.74 & 5 & 92.16 \\
10 & 86.20 & - & - \\
20 & 85.40 & 20 & 87.20 \\
30 & 76.90 & 30 & 78.82 \\
45 & 75.88 & 45 & 71.81 \\
60 & 72.46 & - & - \\
80 & 49.65 & 80 & 50.67 \\
90 & 44.52 & 90 & 46.26
\end{tabular}

Table 6. CEF levels obtained after exposure to thermal $\left(60^{\circ} \mathrm{C}\right)$ evaluated by HPLC and microbiological method.

\section{HPLC Microbiological assay}

\begin{tabular}{lccc}
\hline $\begin{array}{c}\text { Time } \\
\text { (minutes) }\end{array}$ & CEF (\%) & Time (minutes) & CEF (\%) \\
\hline 5 & 100.03 & 5 & 98.60 \\
15 & 98.16 & - & - \\
20 & 96.17 & 20 & 93.73 \\
30 & 88.24 & - & - \\
45 & 80.01 & 45 & 82.77 \\
60 & 71.25 & 60 & 75.22 \\
90 & 64.35 & 90 & 65.13 \\
120 & 55.05 & 120 & 55.60 \\
\hline
\end{tabular}

\section{Comparison of Methods}

The results obtained in the quantitative determination of $\mathrm{CEF}$ by agar diffusion bioassay were statistically compared to the drug content determined by HPLC method. For the microbiological assay method, the mean drug amount found $109.42 \% \pm 1.13 \%$ and for the HPLC method, $110.0 \% \pm 0.57 \%$. These results were statistically analyzed using Student's $t$ test and indicated that there was no significant difference between the methods ( $p>$ $5 \%)$.

\section{Cytotoxicity assay}

Cytotoxicity assay with MTT method was performed to evaluate the effect of the degraded structures in relation to the intact molecule. Results shown in Fig. 5, the sample exposure to thermal degradation at $60{ }^{\circ} \mathrm{C}$ at $1 \mu \mathrm{g} \cdot \mathrm{mL}^{-1}$ not present a significant difference when compared to the negative control and with the sample in the normal condition at the same concentration. However, other concentrations tested presented a significant difference when compared to the negative control, therefore both normal and degraded samples showed significant cell death.

However, sample was exposure to photolytic degradation UVC light (Fig. 6) in the normal condition at the concentration of $1.0 \mu \mathrm{g} \cdot \mathrm{mL}^{-1}$, is not a significant synthesis of cellular viability when compared to the negative control (NC). Nevertheless, a sample in the same concentration submitted to degradation showed a significant difference in relation to the $\mathrm{NC}$ and the sample in the normal condition. When the other concentrations were compared between a normal condition and a degraded condition did not present significant difference, so it is the same profile of cell death. 


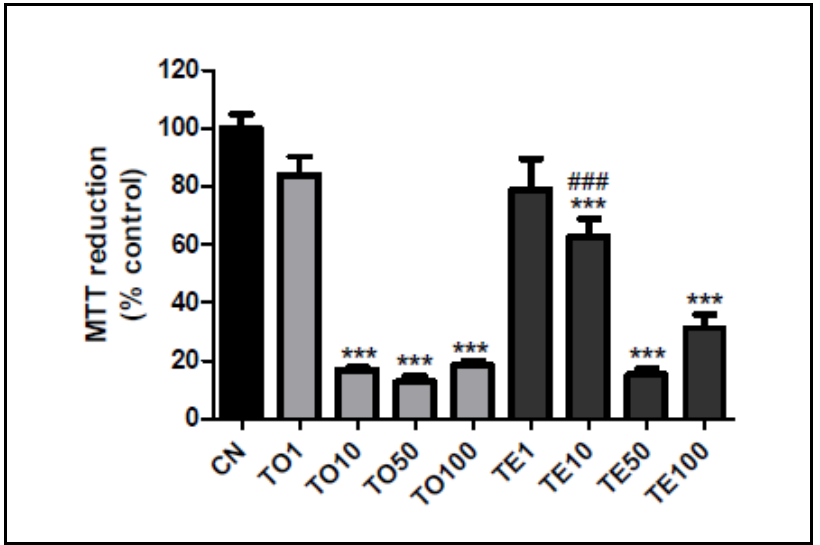

Figure 5. Results obtained for CEF sample in the normal condition (T0) and submitted to thermal degradation 60 ${ }^{\circ} \mathrm{C}$ (TE) by mitochondrial metabolic activity (MTT) assay. Values of $100 \%$ indicate total viability (NC). *** $\mathrm{P}$ $<0.001$ when compared to the negative control $(\mathrm{CN})$. \#\#\# $\mathrm{P}<0.001$ by comparing each concentration of TO with a corresponding concentration of TE.

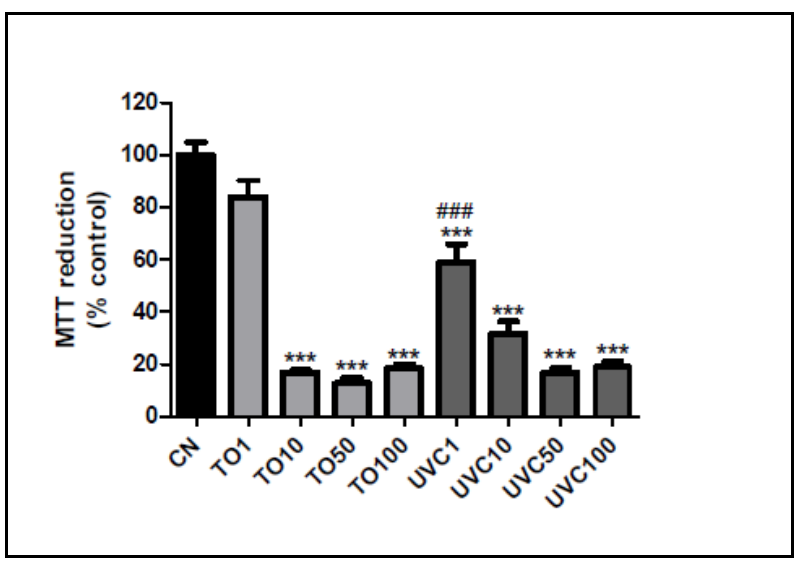

Figure 6. Results obtained for the CEF sample under normal conditions (T0) and submitted to UVC photolytic degradation (UVC) by mitochondrial metabolic activity test (MTT). Values of $100 \%$ indicate total viability (NC).*** $\mathrm{P}<0.001$ when compared to the negative control (CN). \#\#\# P <0.001, comparing each concentration of $\mathrm{TO}$ with the corresponding concentration of TE.

\section{Conclusions}

Microbiological assay and analytical methodology developed by HPLC were validated and demonstrated to be specific, linear, precise, accurate and robust to quantify CEF. The comparison of the proposed methods for quantitative determination of CEF, did not present statistically significant differences, therefore, these can be interchangeable. In this way, the developed methods can be used in the quality control of this drug, thus the bioassay can be a reliable alternative for the laboratory routine.

The preliminary stability study showed instability of the drug when exposure to UVC radiation, at $60{ }^{\circ} \mathrm{C}$, acid hydrolysis and oxidation. When evaluating the kinetics of thermal stability at $60{ }^{\circ} \mathrm{C}$, it indicates a second-order reaction and for UVC photolytic stability it indicates a zero-order reaction. These results were obtained by both the microbiological method and the chromatographic method.

The cytotoxicity assay performed with the drug degraded against UVC and non-degraded light showed cytotoxicity at the tested concentrations $(1.0,10.0,50.0$ and 100.0 $\left.\mu \mathrm{g} . \mathrm{mL}^{-1}\right)$. When the sample was subjected to thermal degradation at $60{ }^{\circ} \mathrm{C}$ and non-degraded, they showed cytotoxicity at concentrations of 10,50 and $100 \mu \mathrm{g} \cdot \mathrm{mL}^{-1}$. This result suggests that the drug, even presenting cytotoxicity in front of the test, requires the execution of other in vitro tests for a more effective conclusion of this parameter analyzed.

\section{Acknowledgments}

The authors are grateful to Coordenação de Aperfeiçoamento de Pessoal de Nível Superior (CAPES) for financial support and for granting research fellowships.

\section{Conflict of interest}

The authors declare no conflicts of interest.

\section{References}

1. Eisenstein BI. Treatment challenges in the management of complicated skin and soft-tissue infections, Clin. Microbiol. Infec. 2008; 14:17-25.

2. White B, Seaton AR, Complicated skin and soft tissue infections: literature review of evidence for and experience with daptomycin, Infec. and Drug Resist. 2011; 4: 115.

3. Kadosaki LL, Sousa SF, Borges JCM, Análise do uso e da resistência bacteriana aos antimicrobianos em nível hospitalar. Rev. Bras. Farm. 2012; 93: 128-135.

4. Brunton LL, Lazo JS, Parker KL, Goodman e Gilman: As Bases Farmacológicas da Terapêutica. McGraw-Hill: Brasil; 2006.

5. Lichtenfels E, Lucas ML, Webster, R, D'azevedo PA. Profilaxia antimicrobiana em cirurgia vascular periférica: cefalosporina ainda é o padrão-ouro? J. Vasc. Bras. 2007: 6; 378-387.

6. Suarez C, Gudiol F, Antibióticos betalactámicos. Enferm. Infec. Micr. Cl. 27 (2009) 116-129.

7. Guimarães DO, Momesso LDS, Pupo MT, Antibióticos: importância terapêutica e perspectivas para a descoberta e desenvolvimento de novos agentes. Quim. Nova. 2010: 33; 667-679.

8. Mpenge MA, Macgowan AP, Ceftaroline in the management of complicated skin and soft tissue infections and community acquired pneumonia. Ther. Clin. Risk. Manag. 2015: 11; 565.

9. SBOC Sociedade Brasileira de Oncologia Clínica BR, ANVISA aprova Zinforo. Available from: http://www.sboc.org.br/anvisa-aprova-zinforoceftarolina-fosamila-para-infeccoes-complicadas-de- 
pele-e-tecidos-moles-e-pneumonia-adquirida-nacomunidade/, 2020 (Accessed 01.05.20).

10. United States Pharmacopeia USP 39. Rockville: United States Pharmacopeial Convention, 2016.

11. I.C.H. Harmonised Tripartite Guideline: Validation of Analytical Procedures: Methodology, ICH Steering Committee, Suiça, 2005.

12. Brasil. Agência Nacional de Vigilância Sanitária. Resolução n. 899, de 29 de maio de 2003. Determina a publicação do guia para validação de métodos analíticos e bioanalíticos. Diário Oficial da República Federativa do Brasil, Brasília/DF, 2003.

13. Farmacopeia Brasileira, Agência Nacional de Vigilância Sanitária (ANVISA), Brasília, 2010.

14. Nudelman NS, Estabilidad de medicamentos, first ed., El atheneo, Buenos Aires, 1975.
15. Rossato LG, Costa VM, Vilas-boas V, Bastos ML, Rolo A, Palmeira C, Remião F, Therapeutic concentrations of mitoxantrone elicit energetic imbalance in $\mathrm{H} 9 \mathrm{c} 2$ cells as an earlier event. Cardiovasc. Toxicol. 2013: 13; 413-425.

16. Dart RK. Microbiology for the analytical chemist, The Royal Society of Chemistry, Cambridge, UK, 1996.

17. WHO. The International Pharmacopoeia. World Health Organization. 4 ed., $3^{\text {rd }}$ Supplement. 2013.

18. Japanese Pharmacopoeia, sixteen ed., The Society of Japanese Pharmacopoeia, Tokyo, 2011.

19. European Pharmacopeia, fifth ed. European Directorate for the Quality of Medicines, Strasbourg Cedex, France, 2005. 